\title{
Adamantinoma-like variant of Ewing sarcoma in the metatarsal bone after chemotherapy: Report of a case successfully treated with a pedicled osteocutaneous fibular transfer
}

\author{
Yolandi Anne Marais ( $\nabla$ ymarais87@sun.ac.za ) \\ Stellenbosch University https://orcid.org/0000-0003-1170-6378 \\ Aaron Saini \\ Stellenbosch University \\ Nando Ferreira \\ Stellenbosch University \\ Kershinee Reddy \\ Stellenbosch University \\ Alexander Zühlke \\ Stellenbosch University \\ Nelmarie Rossouw \\ Stellenbosch University \\ Stefan Dan Zaharie \\ Stellenbosch University \\ Pawel Tomasz Schubert \\ Stellenbosch University
}

\section{Case Report}

Keywords: Ewing sarcoma, Adamantinoma-like Ewing sarcoma, P40, P63, Squamous differentiation, neoadjuvant, Osteocutaneous fibular transfer

Posted Date: April 26th, 2021

DOl: https://doi.org/10.21203/rs.3.rs-96041/v3

License: (c) (1) This work is licensed under a Creative Commons Attribution 4.0 International License. Read Full License 


\section{Abstract}

Adamantinoma-like Ewing sarcoma is a rare variant of Ewing sarcoma known to have histologic and immunohistochemical evidence of squamous differentiation. This variant most commonly occurs in the head and neck region with a few cases reported in long bones of the limbs. It may be associated with poorer clinical outcome and could pose a diagnostic challenge(s) particularly if it occurs in older patients or as a metastatic lesion. We present a case of Ewing sarcoma in the metatarsal of an 11 year old boy that manifested adamantinoma-like morphology after neo-adjuvant chemotherapy. Chemotherapy has been reported to induce neuronal maturation and rhabdoid morphology in cases of Ewing sarcoma, but no reports of treatment induced squamous differentiation with P40/P63 expression have been demonstrated. This is also the first documented case to use a pedicled osteocutaneous fibular transfer in a metatarsal malignancy, which is usually treated by either ray or below knee amputation.

\section{Introduction}

Ewing sarcoma (EWS) is a small round cell sarcoma typically arising in the diaphyseal and metadiaphyseal regions of long bones, predominantly in children and young adults, but can also be seen in soft tissues (particularly of the trunk). It shows gene fusions involving a member of the Ewing family tumor (EFT) family of genes and a member of the erythroblast transformation-specific (ETS) family of transcription factors. Up to $85 \%$ of cases harbor a $t(11 ; 22)(q 24 ; q 12)$ resulting in EWS RNA-binding protein 1 and friend leukemia integration 1 transcription factor (EWSR1-FLI1) gene fusion and up to $25 \%$ of cases express cytokeratins. ${ }^{1-6}$ Numerous histological variants exist, namely classic, atypical/large cell, sclerosing, spindle cell sarcoma-like, and also one that shows squamous differentiation, called adamantinoma-like Ewing sarcoma (ALES). This latter variant presents more commonly in the head and neck region with only a few reported cases which involved the appendicular skeleton. ${ }^{7-23}$ With this case report, we present a metatarsal tumor that showed adamantinoma-like features with P40/P63 expression after neoadjuvant chemotherapy.

\section{Case Report}

A 11-year-old male patient presented with a history of a painless mass involving the first metatarsal of the left foot that was gradually enlarging over the preceding year. A local examination confirmed a firm, $80 \times 30 \mathrm{~mm}$ mass involving the first metatarsal of the left foot. Ankle's range of motion was full and painless. Systemic examination did not reveal any abnormalities and laboratory investigations were unremarkable.

Plain radiographs showed mixed lytic and sclerotic changes involving the entire first metatarsal, with an indistinct permeative appearance of the cortex, associated periosteal reaction, and a subtle soft-tissue component (Figure 1A). A magnetic resonance imaging (MRI) scan showed a diffuse aggressive destructive process involving the entire first metatarsal, with heterogeneous medullary cavity enhancement, an aggressive periosteal reaction, and breach of the cortices. The lesion appeared 
heterogeneous, hypointense, and isointense on T1-weighted images and heterogeneous hyperintense on T2-weighted images. An associated soft-tissue component encased the metatarsal and illustrated postcontrast enhancement (Figure 1B). Systemic staging included a fluorodeoxyglucose positron emission tomography/computed tomography (F-18 FDG PET/CT) scan that showed several skeletal lesions including the left humerus, lumbar spine, and the pelvis. An incisional biopsy confirmed the diagnosis of EWS with EWSR1 rearrangement with fluorescence in situ hybridization (FISH).

The patient received emergency radiotherapy of the spinal column prior to commencement of neoadjuvant chemotherapy after developing symptoms related to spinal cord compression secondary to skeletal metastases. After radiotherapy, neoadjuvant chemotherapy was started according to the Children's Oncology Group EWS Protocol (AEWS0031). The duration of this chemotherapy regimen spans 48 weeks and comprises courses of vincristine (V) $(1.5 \mathrm{mg} / \mathrm{m} 2$ /dose), doxorubicin (D) $(75 \mathrm{mg} / \mathrm{m} 2$ / dose), cyclophosphamide (C) $(1.2 \mathrm{~g} / \mathrm{m} 2 /$ dose) (VDC) alternating at intervals with courses of ifosfamide $(1.8 \mathrm{~g} / \mathrm{m} 2 /$ day for 5 days per course) and etoposide $100 \mathrm{mg} / \mathrm{m} 2 /$ day for 5 days per course) (IE). The patient received 5 cycles of neoadjuvant chemotherapy comprising VDC/IE before local and systemic staging was repeated to assess response to the chemotherapy. A repeat MRI scan confirmed the permeative destructive process of the first metatarsal with an interval decrease in the size of the associated soft-tissue component (Figure 1C). The follow-up positron emission tomography/computed tomography (PET/CT) showed evidence of residual disease in the known primary of the left foot with no evidence of disease elsewhere.

Definitive surgical management consisted of wide excision of the first metatarsal through a dorsomedial approach, including resection of the biopsy tract (Figure 2A). Reconstruction of the bone and soft-tissue defect was accomplished by an ipsilateral pedicled osteocutaneous fibula flap (Figure 2B). Although amputation was considered given the high risk of positive margins, the decision to perform wide resection and reconstruction was based on an extensive discussion between the patient, orthopedic oncological surgeon, and pediatric oncologist. Another contributing factor was that the patient presented with several skeletal metastases that showed an interval decrease in size on the repeat MRI. Once all wounds had healed, adjuvant chemotherapy, consisting of VDC and IE, was recommenced and weight bearing was allowed in a supportive boot. Clinical review at 3 months found a plantigrade sensate foot with no instability of the hallux (Figure $2 \mathrm{C}$ ). On completion of the chemotherapy regimen, the patient will receive adjuvant radiotherapy for positive surgical margins.

\section{Histology}

Initial biopsy:

The pretreatment incisional biopsy consisted of a single fragment measuring $16 \times 9 \times 7 \mathrm{~mm}$ and showed a lesion composed of invasive nests of uniform small round cells with round nuclei containing finely stippled chromatin and inconspicuous nucleoli, scant clear to eosinophilic cytoplasm, and indistinct cytoplasmic membranes (Figure 3A). Immunohistochemical studies showed membranous expression of 
cluster of differentiation 99 (CD99) (Figure 3C) and nuclear expression of FLI1 (Figure 3D) in the tumor cells. FISH revealed rearrangement of the EWSR1 gene.

\section{Resection specimen:}

Macroscopically, the specimen consisted of the left first metatarsal with overlying skin and surrounding soft tissue and measured $60 \times 50 \times 35 \mathrm{~mm}$. On the cut section, a white-gray lesion was present in the periosteal soft tissue with areas of hemorrhage. Microscopically, the residual tumor was mostly present in the soft-tissue infero-medial to the metatarsal with scant microscopic foci of residual tumor in the medullary cavity of the metatarsus. Histologically, it showed typical features of EWS as seen on the initial biopsy, but now with widespread squamous differentiation in the form of prominent eosinophilic cytoplasm and frank keratin pearl formation (Figure 3B). Areas of necrosis, hemosiderin-laden macrophages, foamy macrophages, calcification, and stromal fibrosis were observed, related to treatment effect/response. Immunohistochemical studies have shown CD99 and FLI1 expression as seen in the previous biopsy. Additional immunohistochemical stains were performed on both (prechemotherapy and postchemotherapy) specimens and included AE1/AE3, cytokeratin 5 (CK5), 34ßE12, P63, and P40 (Table 1). AE1/AE3 showed positive staining in both specimens, but P63 and P40 (Figure 4) were only positive in the resection specimen on both decalcified and nondecalcified tissues. CK5 and 34ßE12 showed reactivity in single isolated cells in the initial biopsy but were diffusely positive in the resection specimen. Desmin, erythroblast transformation-specific related gene (ERG), and S100 immunohistochemical stains were negative and argues against the possibility of other small round cell lesions such as a desmoplastic small round cell tumor that can also express CD99 and cytokeratins.

Table 1. Immunohistochemical staining profile: + (positive in single cells), ++ (diffusely positive), (negative).

\begin{tabular}{|lll|}
\hline Immunohistochemical stain & Initial biopsy & Resection specimen \\
\hline CD99 & ++ & ++ \\
\hline FLI-1 & ++ & ++ \\
AE1/AE3 & ++ & ++ \\
P63 & - & ++ \\
P40 & - & ++ \\
CK5 & + & ++ \\
\hline $34 \beta E 12$ & + & ++ \\
\hline
\end{tabular}

\section{Discussion}


In this case, the initial incisional biopsy showed morphological features in keeping with "classic" EWS, but with morphological and immunophenotypical changes to an ALES variant after chemotherapy. We considered that this change may be due to one of the following: (1) undersampling of the tumor on the initial incisional biopsy, (2) emergence/persistence of a more chemotherapy-resistant clone, or (3) alterations in the tumor morphology and/or immunophenotype caused by chemotherapy.

To address the question of chemotherapy-related alterations: The chemotherapy response of EWS is graded according to the Pediatric Oncology Group Study24 using the typically seen changes of necrosis, hemorrhage, cystic degeneration, calcification, ossification, and fibrosis. The grading of chemotherapeutic response has prognostic and therapeutic significance as it plays a role in chemotherapy agent selection for continuation chemotherapy. ${ }^{24-27}$

Other reported morphological changes in EWS after chemotherapy include neuronal maturation with rosette formation and gangliocytic phenotype differentiation, but rhabdoid change has also been described though the tumor maintained its immunophenotype. ${ }^{28,29}$ Knezevich et al ${ }^{30}$ described the loss of EWS/FLI1 gene fusion in the recurrent tumor, while Smith et al ${ }^{31}$ described a different genetic alteration in one of the tumor nodules. No case reports of squamous differentiation (including keratin pearl formation) with P40/P63 expression after chemotherapy could be found on a literature search. ${ }^{32}$

In our case, the original tumor biopsy, even though it might not have been representative of the entire tumor, was P40 and P63 negative and only showed expression of these immunomarkers on the resection specimen (after neoadjuvant chemotherapy). CK5 and $34 \beta E 12$ showed diffuse staining in the resection specimen while only single isolated cells were reactive in the initial biopsy. Classic EWS, in $25 \%$ of cases, may express keratins such as CAM5.2, AE1/AE3, and MNF-116. 3,4

EWS fusion was positive on the initial biopsy using FISH, but the translocation partner remains uncertain as dual-fusion FISH probes and polymerase chain reaction (PCR) are not available in our setting.

It would hence seem that this phenotype and immunophenotype was not present initially and only appeared/persisted after chemotherapy.

One research paper suggested that ALES may be associated with a more aggressive clinical behavior and a poorer outcome. ${ }^{7}$ If in our case, the ALES is indeed due to the persistence of a more resistant clone, this could support this claim but additional research is needed.

Apart from the unique histological findings of this case, a novel reconstructive strategy was also employed. Reconstruction of the first metatarsal is more critical than the lesser metatarsals given its role in progression through the gait cycle. In the context of trauma, first ray reconstruction using both free and pedicled fibula flaps was described as early as $1991 .{ }^{33}$ Wang et al ${ }^{34}$ described a series of 4 patients who had metatarsal reconstruction, 2 of the first ray and 2 of the lesser, using pedicled fibula flaps. More recently, St. Hilaire et $\mathrm{al}^{35}$ described computer assisted virtual surgical planning in a case of first metatarsal reconstruction using a free fibula flap. Malignancy of the metatarsals, however, has limited 
options in terms of salvage surgery. Management of primary bone tumors of the lesser metatarsals usually consists of ray ${ }^{36}$ or below-knee amputation. ${ }^{34,35}$ Few reports exist on the use of autologous vascularized fibula grafts, either free or pedicled, for forefoot reconstruction. Borthakur et al ${ }^{37}$ described vascularized free fibula transfer after resection of a first ray osteosarcoma. Toriyama et al ${ }^{38}$ reported concomitant first and second metatarsal reconstruction following resection for chondrosarcoma using a free vascularized double-barreled fibula graft, and Toma et al ${ }^{39}$ reported a series of 6 cases of metatarsal primary bone tumors resected and reconstructed with a free vascularized fibula graft, including the first and lesser rays. To the best of our knowledge, our case is the first description of a pedicled vascularized fibula graft used for the reconstruction of the first metatarsal after resection for malignancy.

\section{Conclusion}

This phenotypical and immunophenotypical change from the "classic" variant to the "adamantinomalike" variant (with squamous differentiation and P63/P40 expression) is very interesting, and the mechanism of this change is not fully understood with regard to its relationship to neoadjuvant chemotherapy. There is also some literature that suggests that the latter variant may carry a poorer prognosis.

Such a lesion may cause diagnostic dilemmas with a number of neoplasms that also show small cell morphology with squamous differentiation such as the basaloid variant of squamous cell carcinoma or nuclear protein in testis (NUT)-midline carcinoma. This scenario might arise, especially if confronted by a small biopsy from a metastatic lesion of such a tumor either in an older patient, in the head and neck region, or if there was a history of EWS for which they received chemotherapy.

Thus an adequate awareness of this variant, the potential chemotherapy-related changes, immunohistochemical staining patterns, and the use of appropriate molecular testing to establish a correct diagnosis is advised.

\section{Declarations}

\section{Declaration of conflicting interests:}

The author(s) declared no potential conflicts of interest with respect to the research, authorship, and/or publication of this article.

\section{Funding:}

The author(s) received no financial support for the research, authorship, and/or publication of this article.

\section{Ethics approval and consent to participate:}


Ethical approval was obtained from the Stellenbosch University Health Research Ethics Committee C20/09/030.

\section{Informed consent:}

Written informed consent was obtained from the parent of the patient for publication of this case report and any accompanying images. A copy of the written consent is available for review by the Editor-in-Chief of this journal.

\section{Trial Registration:}

Not applicable, because this article does not contain any clinical trials.

\section{ORCID iD:}

Yolandi A. Marais https://orcid.org/0000-0003-1170-6378

\section{Published article available:}

DOI: $10.1177 / 10668969211001449$

\section{References}

1. Choi E-YK, Gardner JM, Lucas DR, McHugh JB, Patel RM. Ewing sarcoma. Semin Diagn Pathol. 2014;31(1):39-47.

2. Antonescu C. Soft Tissue And Bone Tumours. 5th ed. International Agency for Research on Cancer; 2020.

3. Elbashier SHA, Nazarina AR, Looi LM. Cytokeratin immunoreactivity in Ewing sarcoma/ primitive neuroectodermal tumour. Malays J Pathol. 2013;35(2):139-145.

4. Gu M, Antonescu CR, Guiter G, Huvos AG, Ladanyi M, Zakowski MF. Cytokeratin immunoreactivity in Ewing's sarcoma: Prevalence in 50 cases confirmed by molecular diagnostic studies. Am J Surg Pathol. 2000;24(3):410-416.

5. Srivastava A, Rosenberg AE, Selig M, Rubin BP, Nielsen GP. Keratin-positive Ewing's sarcoma: an ultrastructural study of 12 cases. Int J Surg Pathol. 2005;13(1):43-50.

6. Kilpatrick SE, Reith JD, Rubin B. Ewing sarcoma and the history of similar and possibly related small round cell tumors: From whence have we come and where are we going? Adv Anat Pathol. 2018;25(5):314-326.

7. Bridge JA, Fidler ME, Neff JR, et al. Adamantinoma-like Ewing's sarcoma: genomic confirmation, phenotypic drift. Am J Surg Pathol. 1999;23(2):159-165.

8. Hauben E, van den Broek LC, Van Marck E, Hogendoorn PC. Adamantinoma-like Ewing's sarcoma and Ewing's-like adamantinoma. The t(11; 22), t(21; 22) status. J Pathol. 2001;195(2):218-221. 
9. Llombart-Bosch A, Machado I, Navarro S, et al. Histological heterogeneity of Ewing's sarcoma/PNET: an immunohistochemical analysis of 415 genetically confirmed cases with clinical support. Virchows Arch. 2009;455(5):397-411.

10. Rooper LM, Bishop JA. Soft tissue special issue: Adamantinoma-like Ewing sarcoma of the head and neck: A practical review of a challenging emerging entity. Head Neck Pathol. 2020;14(1):59-69.

11. Folpe AL, Goldblum JR, Rubin BP, et al. Morphologic and immunophenotypic diversity in Ewing family tumors: a study of 66 genetically confirmed cases. Am J Surg Pathol. 2005;29(8):1025-1033.

12. Weinreb I, Goldstein D, Perez-Ordoñez B. Primary extraskeletal Ewing family tumor with complex epithelial differentiation: a unique case arising in the lateral neck presenting with Horner syndrome. Am J Surg Pathol. 2008;32(11):1742-1748.

13. Hafezi S, Seethala RR, Stelow EB, et al. Ewing's family of tumors of the sinonasal tract and maxillary bone. Head Neck Pathol. 2011;5(1):8-16.

14. Kikuchi Y, Kishimoto T, Ota S, et al. Adamantinoma-like Ewing family tumor of soft tissue associated with the vagus nerve: a case report and review of the literature: A case report and review of the literature. Am J Surg Pathol. 2013;37(5):772-779.

15. Bishop JA, Alaggio R, Zhang L, Seethala RR, Antonescu CR. Adamantinoma-like Ewing family tumors of the head and neck: A pitfall in the differential diagnosis of basaloid and myoepithelial carcinomas. Am J Surg Pathol. 2015;39(9):1267-1274.

16. Lezcano C, Clarke MR, Zhang L, Antonescu CR, Seethala RR. Adamantinoma-like Ewing sarcoma mimicking basal cell adenocarcinoma of the parotid gland: a case report and review of the literature. Head Neck Pathol. 2015;9(2):280-285.

17. Bishop JA. Recently described neoplasms of the sinonasal tract. Semin Diagn Pathol. 2016;33(2):6270.

18. Alexiev BA, Tumer Y, Bishop JA. Sinonasal adamantinoma-like Ewing sarcoma: A case report. Pathol Res Pract. 2017;213(4):422-426.

19. Lilo MT, Bishop JA, Olson MT, Ali SZ. Adamantinoma-like Ewing sarcoma of the parotid gland: Cytopathologic findings and differential diagnosis. Diagn Cytopathol. 2018;46(3):263-266.

20. Morlote D, Harada S, Lindeman B, Stevens TM. Adamantinoma-like Ewing sarcoma of the thyroid: A case report and review of the literature. Head Neck Pathol. 2019;13(4):618-623.

21. Rooper LM, Jo VY, Antonescu CR, et al. Adamantinoma-like Ewing sarcoma of the salivary glands: $A$ newly recognized mimicker of basaloid salivary carcinomas. Am J Surg Pathol. 2019;43(2):187-194.

22. Umamahesweran S, Gochhait D, Jayachandran J, Govindarajan K, Siddaraju N, Srinivas BH. Cytomorphological features of adamantinoma-like Ewing's sarcoma in parotid masquerading as sialoblastoma in a paediatric patient. Cytopathology. 2020;31(3):228-231.

23. Fujii $\mathrm{H}$, Honoki K, Enomoto Y, et al. Adamantinoma-like Ewing's sarcoma with EWS-FLI1 fusion gene: a case report. Virchows Arch. 2006;449(5):579-584.

24. Hameed M. Small round cell tumors of bone. Arch Pathol Lab Med. 2007;131(2):192-204. 
25. van der Woude HJ, Bloem JL, Taminiau AH, Nooy MA, Hogendoorn PC. Classification of histopathologic changes following chemotherapy in Ewing's sarcoma of bone. Skeletal Radiol. 1994;23(7):501-507.

26. García-Castellano JM, Atallah Yordi N, Reyes C, Healey JH. Histopathologic and radiologic assessment of chemotherapeutic response in Ewing's sarcoma: A review. Sarcoma. 2012;2012:357424.

27. Min HS, Kang HG, Ro JY. Therapy related changes in osteosarcoma and Ewing sarcoma of bone. Open Pathol J. 2009;3(2):99-105.

28. Salet MCW, Vogels R, Brons P, Schreuder B, Flucke U. Maturation toward neuronal tissue in a Ewing sarcoma of bone after chemotherapy. Diagn Pathol. 2016;11(1):74.

29. Ushigome S, Shimoda T, Nikaido T, et al. Primitive neuroectodermal tumors of bone and soft tissue. With reference to histologic differentiation in primary or metastatic foci. Acta Pathol Jpn. 1992;42(7):483-493.

30. Knezevich SR, Hendson G, Mathers JA, et al. Absence of detectable EWS/FLI1 expression after therapy-induced neural differentiation in Ewing sarcoma. Hum Pathol. 1998;29(3):289-294.

31. Smith LM, Adams RH, Brothman AR, Vanderhooft SL, Coffin CM. Peripheral primitive neuroectodermal tumor presenting with diffuse cutaneous involvement and 7;22 translocation. Med Pediatr Oncol. 1998;30(6):357-363.

32. Lowichik A, Zhou H, Pysher TJ, Smith L, Lemons R, Coffin CM. Therapy associated changes in childhood tumors. Adv Anat Pathol. 2000;7(6):341-359.

33. Rajacic N, Ebrahim MK, Grgurinovic S, Starovic B. Foot reconstruction using vascularised fibula. Br J Plast Surg. 1993;46(4):317-321.

34. Wang C-Y, Han P, Chai Y-M, Lu S-D, Zhong W-R. Pedicled fibular flap for reconstruction of composite defects in foot. Injury. 2015;46(2):405-410.

35. St. Hilaire H, Steele TN, Delatte S, Hebert CK, Canizares O. Metatarsal reconstruction with a fibular osteocutaneous flap: A novel approach utilizing virtual surgical planning. Plast Reconstr Surg Glob Open. 2014;2(11):e258.

36. Peshin C, Das K, Ghaffar AA, Malik SH. Ewings sarcoma of fourth metatarsal: A rare presentation. J Clin Diagn Res. Published online 2019. doi:10.7860/jcdr/2019/37214.12468

37. Borthakur BB, Bannoth S, Boro S, Purkayastha J, Talukdar A, Kalita D. Vascularised fibular graft reconstruction following resection of first metatarsal osteosarcoma: Case report. Indian J Surg Oncol. 2020;11(S1):60-62.

38. Toriyama K, Kamei Y, Yagi S, Uchibori M, Nishida Y, Torii S. Reconstruction of the first and second metatarsals with free vascularised double-barrelled fibular graft after resection of a chondrosarcoma. J Plast Reconstr Aesthet Surg. 2009;62(12):e580-3.

39. Toma CD, Dominkus M, Pfeiffer M, Giovanoli P, Assadian O, Kotz R. Metatarsal reconstruction with use of free vascularized osteomyocutaneous fibular grafts following resection of malignant tumors 
of the midfoot. A series of six cases: A series of six cases. J Bone Joint Surg Am. 2007;89(7):15531564.

\section{Figures}
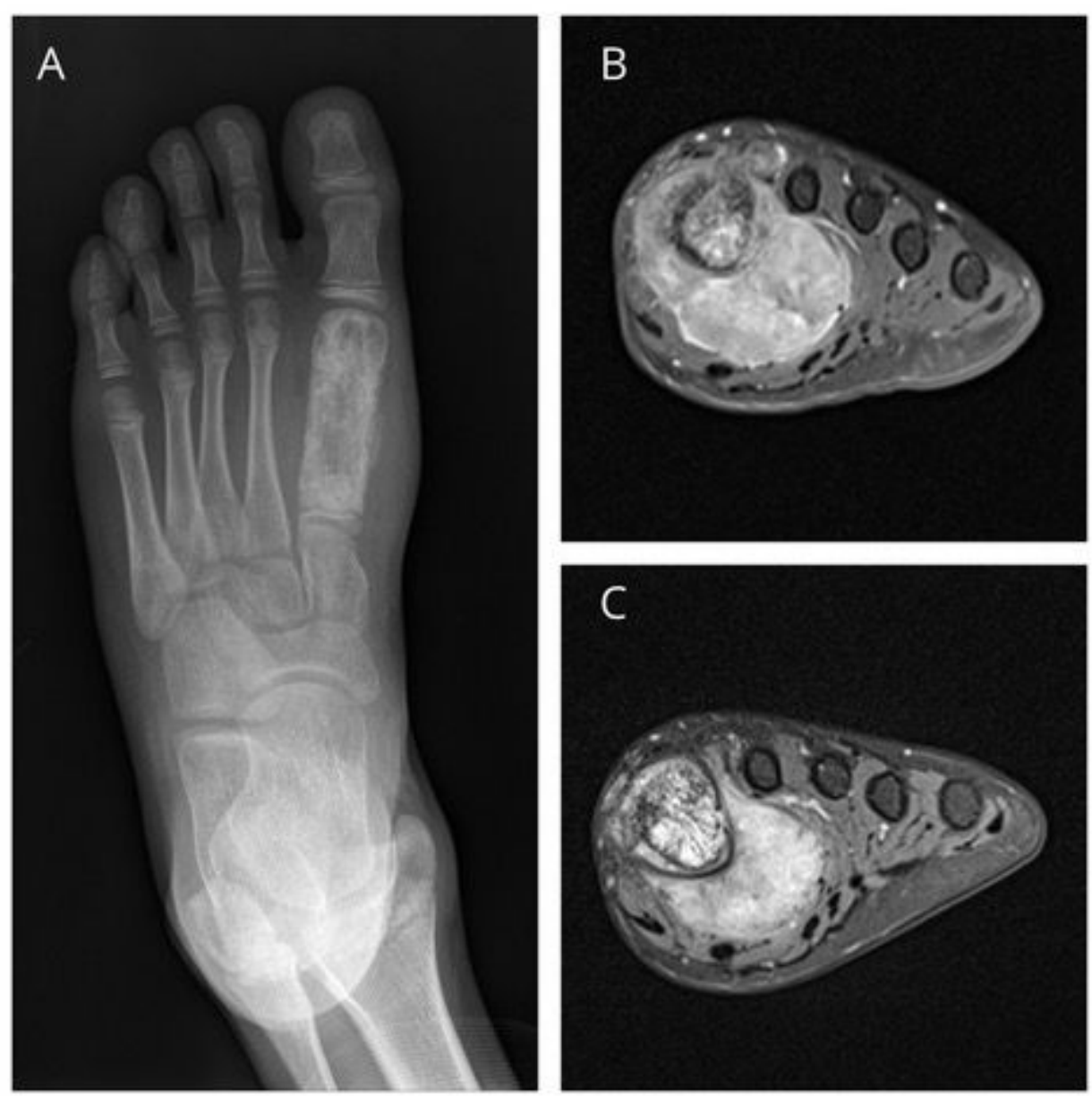

\section{Figure 1}

(A) Anteroposterior radiograph showing a poorly defined mixed lytic and sclerotic lesion of the left first metatarsal. (B) Magnetic resonance imaging scan showing a permeative destructive process involving the first metatarsal and large soft-tissue component encasing the metatarsal. (C) Subsequent interval decrease in size after neoadjuvant chemotherapy. 

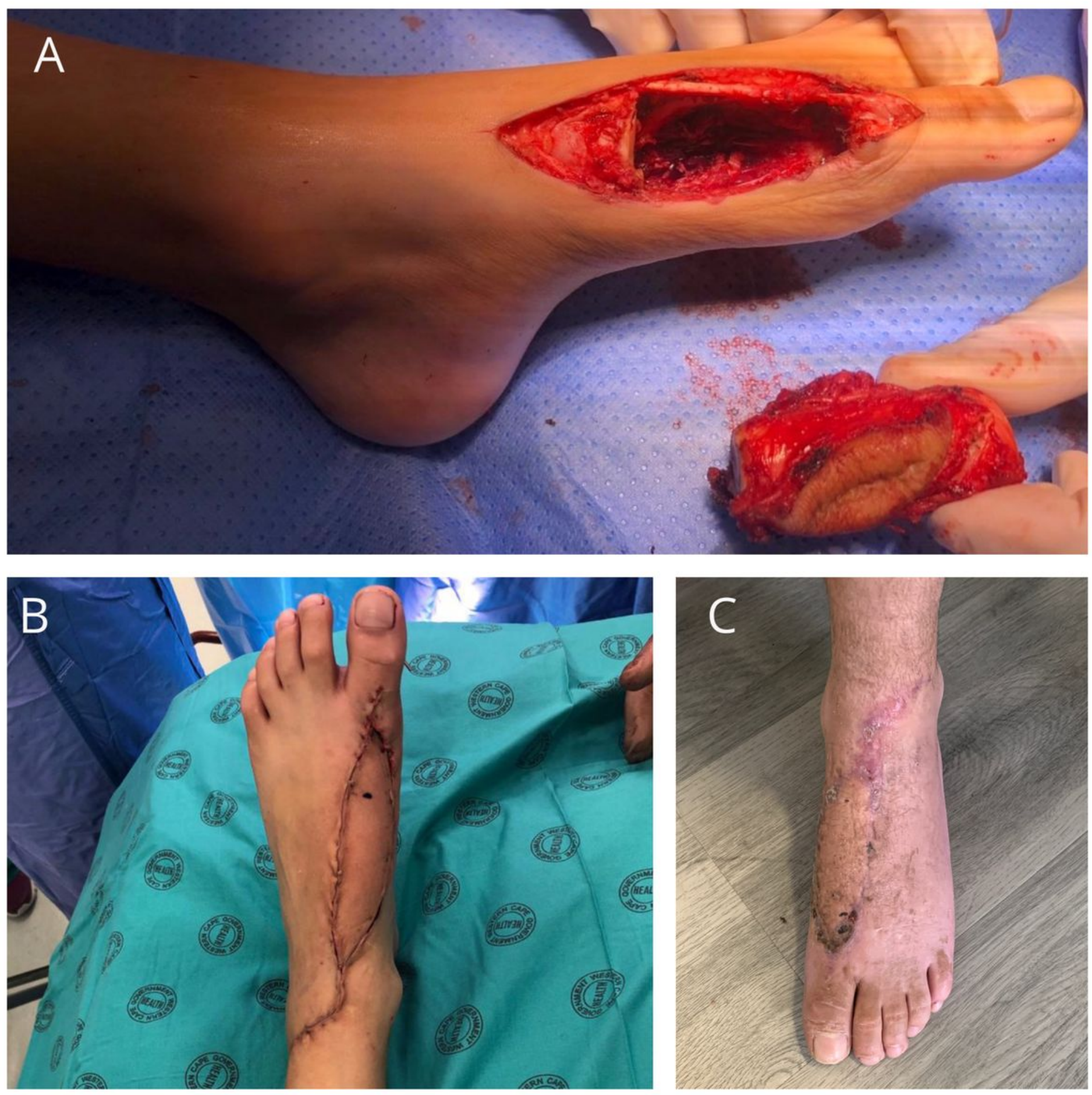

\section{Figure 2}

(A) Wide resection of the first metatarsal through an anteromedial approach. (B) Soft tissue and bony defect reconstructed with an ipsilateral pedicled osteocutaneous fibula flap. (C) Plantigrade foot with healed cutaneous flap, 3 months after surgery. 

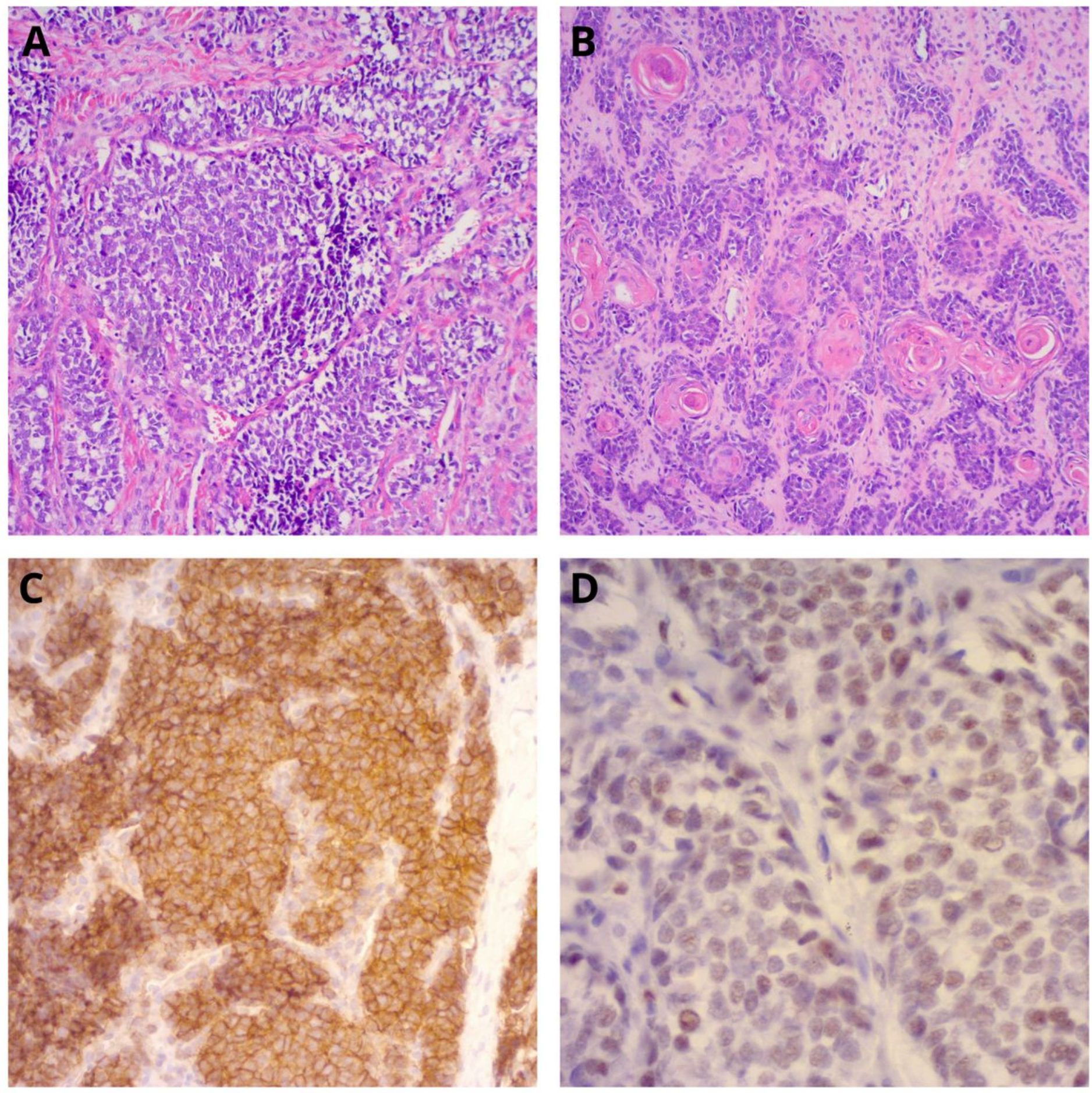

\section{Figure 3}

(A) Microscopic image of the initial biopsy. EWS showing a "classic" growth pattern of nests of small blue round cells; H\&E 100x. (B) Microscopic image of the post neoadjuvant chemotherapy resection specimen. Adamantinoma-like Ewing's sarcoma with squamous differentiation and keratin pearl formation; H\&E 100x. (C) CD99 immunostain of the initial biopsy with membranous and cytoplasmic staining; 200×. (D) FLI1 immunostain of the initial biopsy with nuclear staining; 400x. Abbreviations: 
EWS, Ewing sarcoma; H\&E, hematoxylin and eosin, CD99, cluster of differentiation 99; FLI1, Friend leukemia integration 1 transcription factor.
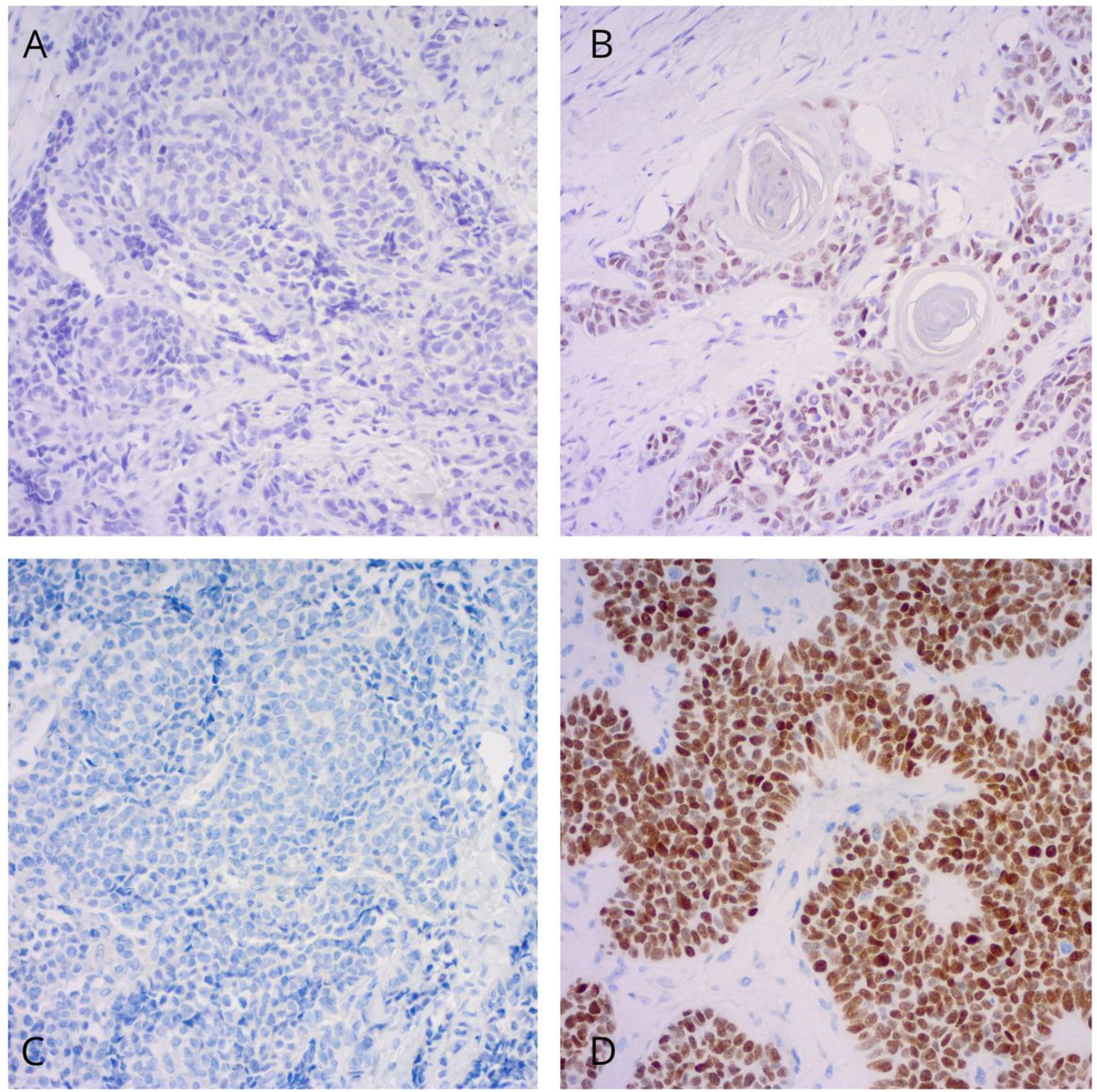

\section{Figure 4}

Immunohistochemical staining profile. (A) Initial Ewing sarcoma with negative P63 immunostain; 200x. (B) Resection specimen adamantinoma-like Ewing sarcoma with positive P63 immunostain; 200x. (C) Initial Ewing sarcoma with negative P40 immunostain; 200x. (D) Resection specimen adamantinoma-like Ewing sarcoma with positive P40 immunostain; 200x. 


\section{Supplementary Files}

This is a list of supplementary files associated with this preprint. Click to download.

- CAREchecklist.pdf 